\title{
The Outlook for Combustion Engines in the Future Transportation System
}

\author{
Vahid Motevalli \\ Associate Dean for Research and Innovation \\ College of Engineering, Tennessee Tech University, USA
}

The pace of innovations in transportation systems have accelerated significantly in the past few years due to advances in the electrification of transportation system. Elon Musk's hyperloop, Tesla's autonomous electric trucks, electric trains and even Fuel Cell electric airplanes will change the nature of transportation in the next decades. Combustion engines have powered our transportation systems throughout the world for nearly two centuries. The combustion engines suitable for transportation systems include the internal combustion engines, gas turbine combustors and a number of other variations in the configurations and combustion modifications. Most of these engines can categorically fall within "internal" and "external" combustion engines. These engines can certainly use a variety of fuels and the complex chemistry of hydrocarbon fuels have made the combustion field, in general, one of the most complex fields in science and engineering. This complexity; chemistry, fluid dynamics and thermal dynamics, have also made both understanding and controlling combustion products most challenging over the years.

Ultimately, two main categories can be used to determine the extent of usefulness of combustion engines in the future transportation system vs. that of electric powertrains. The first category is emission. It is clearly a disadvantage for combustion engines, although one has to consider environmental impact of electrical propulsion systems, including electric storage. The second category is the comparative performance of these propulsion systems. Such comparisons must use clear and appropriate parameters for power and energy, namely power density, energy density, specific power and specific energy.

This keynote address will examine the comparison between combustion engines and electric propulsion systems for transportation application considering both performance and emission characteristics. 